https://doi.org/10.30843/nzpp.2018.71.212

\title{
Biosecurity partnership and collaboration: key similarities and differences between the Australian and New Zealand plant-biosecurity government- industry agreements
}

\author{
Mark S. Bullians ${ }^{1,3,5, \star}$, David A.J. Teulon ${ }^{2,3,5}$, Rebecca Laws ${ }^{4,5}$, Suzy Perry ${ }^{4,5}$ and Gary Hill2,3,5 \\ ${ }^{1}$ The New Zealand Institute for Plant \& Food Research Ltd (PFR), PO Box 92169, Mt Albert, Auckland 1142, \\ New Zealand \\ ${ }^{2}$ PFR, Private Bag 4704, Christchurch 8140, New Zealand \\ ${ }^{3}$ Better Border Biosecurity (www.b3nz.org), New Zealand \\ ${ }^{4}$ Biosecurity Queensland DAF, Ecosciences Precinct, Brisbane QLD 4001, Australia \\ ${ }^{5}$ Plant Biosecurity CRC, University of Canberra, Bruce ACT 2617, Australia \\ *Corresponding author: Mark.Bullians@plantandfood.co.nz
}

New Zealand and Australia have each established legal partnerships between government and industry to improve biosecurity outcomes. Both partnerships take a collaborative approach to build capability and capacity to manage biosecurity risk across the biosecurity system. Key differences between the New Zealand and Australian systems include: the scope of responsibilities and accountability for management of biosecurity pests; governance arrangements; and cost sharing. Key similarities include: a shared role in response decision making; shared costs for pest eradication; advanced agreement on the potential liabilities surrounding pest eradication; provision for compensation to growers for direct costs incurred during an eradication response; minimum commitments to maintain capability and capacity; and an established basis for a transparent, consistent and equitable partnership. The approach taken by both countries encompasses the view that biosecurity outcomes will be improved by building genuine industry-government partnerships. In New Zealand, successes include development of operational agreements, strategies for fruit fly and brown marmorated stink bug, and completion of readiness activities for future incursions of these pests. 